\title{
Synthesis and optical characterization of copper nanoparticles prepared by laser ablation
}

\author{
SAMIRA MONIRI ${ }^{1, *}$, MAHMOOD GHORANNEVISS ${ }^{1}$, MOHAMMAD REZA HANTEHZADEH ${ }^{1}$ \\ and MOHSEN ASADI ASADABAD ${ }^{2}$ \\ ${ }^{1}$ Plasma Physics Research Center, Science and Research Branch, Islamic Azad University, Tehran 1477893855, Iran \\ ${ }^{2}$ Materials Research School, NSTRI, Isfahan 81465-1589, Iran
}

MS received 5 March 2016; accepted 8 June 2016

\begin{abstract}
The remarkable size-tunable properties of nanoparticles (NPs) make them a hot research topic with applications in a wide range of fields. Hence, copper $(\mathrm{Cu})$ colloidal NPs were prepared using laser ablation (Nd:YAG, $1064 \mathrm{~nm}, 7 \mathrm{~ns}, 10 \mathrm{~Hz}, 6000$ pulses) of a copper metal plate at different laser fluences (LFs) in the range of 1-2.5 $\mathrm{J} \mathrm{cm}^{-2}$ in ethylene glycol (EG), at room temperature. Analysis of NPs was carried using different independent techniques such as ultraviolet-visible (UV-vis) spectroscopy; transmission electron microscopy (TEM) and Fourier transform infrared (FTIR) spectroscopy. TEM analysis showed that the NPs were spherical with a bimodal distribution and an average particle size of 5 and $16 \mathrm{~nm}$ influence of $1.2 \mathrm{~J} \mathrm{~cm}^{-2}$, and 9 and $22 \mathrm{~nm}$ at $2 \mathrm{~J} \mathrm{~cm}^{-2}$. The UV-vis spectra of colloidal NPs revealed the maximum absorbance at around $584 \mathrm{~nm}$, indicating the formation of Cu NPs, which supported using FTIR spectra. Furthermore, the absorption spectra confirmed the metallic nature of Cu NPs. FTIR spectroscopy was utilized to verify information about the NPs surface state and chemical bonds constructed in the atom groups apparent on their surface.
\end{abstract}

Keywords. Copper nanoparticles; optical property; LSPR, laser ablation.

\section{Introduction}

Among all nanomaterials, nanoparticles (NPs) are of great interest because of their optical, structural, electronic and thermal properties, compared with their bulk material [1-3]. Among them, NPs made of noble metals like copper with plasmonic properties started to be investigated in the last decades, due to their specific properties, which make them useful for applications in a wide range of fields like cancer treatment, photonics, information technology, materials science, etc. [4].

From a general point of view, $\mathrm{Cu}$ NPs are finding many usages in nanocircuits, nanoelectronics, nanodevices, plasmonic, optics, nanosensors, etc. [5,6].

In particular, copper NPs possess photo-sensitivity and electrical conductivity, which makes them applicable in various technological areas. Furthermore, these particles have antibacterial activity that has been related to their small size and large surface to volume ratio, which permits them to interact with microbial species [5,7]. NPs have been made by a broad variety of techniques. One of them, pulsed laser ablation in liquids (PLAL), has become a popular top-down approach for synthesis of nearly all classes of materials, especially pure NP colloids with controlled geometry and size $[8,9]$. One advantage of this approach is that crystallized NPs can easily be obtained in one-step methods without

*Author for correspondence (sss_moniri@yahoo.com) by-products and impurities [10]. Laser ablation was invented in the 1960s. The origin of laser ablation studies commenced with the birth of the laser itself [4,11]. This technique allows versatile design through selecting suitable solid targets and confining liquids [4,12].

First, a laser pulse is focused on a target immersed in a liquid. Then, the laser ablation process starts with the absorption of the laser pulse energy by electrons that creates a superheated environment. The absorption is followed by energy transfer from excited electrons to the crystal lattice because of photon-atom interaction, which leads to very rapid heating and breakdown of the laser-brightened area, wherein the solvent in contact with the metal and the metal itself are vaporized.

After this, different mechanisms, including the generation, transformation and condensation of laser-produced plasma, can occur in the PLAL process.

The liquid restricts the expansion of the plasma plume, which induces the nucleation and growth of NPs. The produced NPs are electrically charged and thus form stable colloids in appropriate liquids [13-16].

By changing the surface charge of the nuclei, the size and aggregation state of NPs can be controlled [10]. Furthermore, the liquid molecules surrounding the NPs form a protective shell, which prohibits aggregation and allows NPs to be suspended for a long time [15]. However, by tuning several laser parameters such as beam focusing, pulse duration, repetition rate, wavelength and fluence, we can achieve small size dispersion of NPs with high stability. 
Furthermore, the final properties of NPs depend on these laser parameters $[17,18]$. In this work, a single-step PLAL process for production of $\mathrm{Cu}$ NPs was developed; the effect of laser fluence (LF) on the size, morphology, localized surface plasmon resonance (LSPR) and surface states of NPs was evaluated and the findings are presented.

\section{Experimental}

Nd-YAG (neodymium-doped yttrium aluminium garnet) nanosecond laser (Q-PLUS model from Spectrum. A. T. N. Ltd) of $1064 \mathrm{~nm}$ (pulse width: $7 \mathrm{~ns}$, repetition frequency: $10 \mathrm{~Hz}$ ) was utilized as an ablation source. The ablation was made by 6000 pulses of laser at room temperature. The laser beam was centralized on a copper plate with a beam size of $2 \mathrm{~mm}$ in diameter by applying a plano-convex lens with a focal length of $80 \mathrm{~mm}$. The spot size of the laser beam on the surface of copper target was calculated to be $40 \mu \mathrm{m}$. Furthermore, the ablation process was typically done for 10 min at room temperature. The samples were prepared with LF values of $1,1.2,1.5,2$ and $2.2 \mathrm{~J} \mathrm{~cm}^{-2}$, corresponding to laser pulse energy of $31.4,37.6,47.1,62.8$ and $69 \mathrm{~mJ}$, respectively.

The copper plate was first polished by $\mathrm{SiC}$ paper. Then, it was washed with absolute ethanol, acetone and distilled water using ultrasonication for several minutes to eliminate impurity from its surface. Afterwards, the plate (purity: $99.9 \%$, in the form of a rectangle with dimensions of $\sim 12 \times 16 \mathrm{~mm}^{2}$, thickness $\sim 0.5 \mathrm{~mm}$ ), was placed (normal to the laser beam) in a Pyrex container filled with $25 \mathrm{ml}$ ethylene glycol (EG; Merck, Germany) as a solvent. Next, it was located at $7 \mathrm{~mm}$ from the liquid surface. Upon irradiating the copper plate by the laser beam, it was superheated; the material was extruded into the solution. After that, the large amount of NPs produced in the suspension gradually created a yellowish-brown colour with increasing laser pulse number.

Ultraviolet-visible (UV-vis) spectra of colloidal NPs were obtained by absorption in the region of 400-800 nm using a UV-vis-NIR spectrophotometer (Unico model-2100) in a $1 \mathrm{~cm}$ path length spectrometric quartz cell.

The morphology and size distribution of NPs were investigated using a transmission electron microscope (Philips-EM $208 \mathrm{~S}$ ) working at $120 \mathrm{kV}$.

The surface of prepared NPs was studied by a Fourier transform spectrophotometer Nexus 870 (Thermo Nicolet model-USA) in the mid-IR region $\left(4000-400 \mathrm{~cm}^{-1}\right)$.

\section{Results and discussion}

\subsection{UV-visible absorption measurements}

$\mathrm{UV}$-vis spectroscopy is a practical technique that characterizes any optical activity eventuated from noble metal NPs, for instance, $\mathrm{Au}, \mathrm{Pd}, \mathrm{Cu}$ and $\mathrm{Ag}[15,19]$. The optical attributes of NPs alter significantly from those that are seen in bulk material [2].
These NPs represent LSPR bands in the visible region, related to excitation of the conduction electrons of metal NPs after their unique interaction with the electromagnetic field of light [20-23].

The conduction electrons in plasmonic NPs oscillate collectively to only specific wavelengths of light. Therefore, they exhibit selective photon absorption, which can easily be monitored using UV-vis spectroscopy $[1,24]$.

The scattering and absorption properties of spherical metal NPs are characterized by employing the Mie theory. This theory, which was explained in 1908, can be utilized to calculate LSPRs using Maxwell's equations for the small spheres interacting with an electromagnetic field. Gan utilized this theory to study ellipsoidal geometries [25,26].

By changing the shape, size, composition and interparticle spacing of NPs or dielectric environment, LSPR can be tuned. This is the foundation for the application of noble metal NPs as sensitive sensors [21,27]. In general, the existence of a sharp plasmon band near $600 \mathrm{~nm}$ for $\mathrm{Cu}$ demonstrates that $\mathrm{Cu}$ NPs with a spherical shape have been obtained [19].

The spherical and cylindrical particles have a single- and a double-peak absorption spectrum, respectively [23].

The intensity and peak position of the absorption spectrum are specified by the amount and the diameter of NPs, respectively. Furthermore, the absorption at long wavelengths is due to scattering of light by large particles [22,27].

Figure 1 displays the UV-vis spectra of five copper colloidal solutions, as a function of wavelength for different LFs ranging from 1 to $2.5 \mathrm{~J} \mathrm{~cm}^{-2}$. However, the optimum adjusted LF is a very important parameter to increase ablation efficiency [8]. The maximum absorption peaks in the fluences of $1,1.2,1.5,2$ and $2.5 \mathrm{~J} \mathrm{~cm}^{-2}$ are at $584,582,584,584$ and $584 \mathrm{~nm}$, respectively, which correspond to a particle size of copper NPs. From the inset of figure 1, a shift in the absorption peak position with changing LF value can be clearly seen.

In fact, the existence of LSPR absorptions associated with nano-sized nature and spherical shape of $\mathrm{Cu}$ particle is confirmed by the presence of a single peak around 582-584 nm $[1,5]$. In general, the intensity, position and width of the absorption peaks are found also to be dependent upon the LF value.

In fact, the exact position of plasmon absorption depends on several factors, including particle size, shape, solvent type, etc. [28].

In the samples of figure 1, with increasing LF value up to $2.5 \mathrm{~J} \mathrm{~cm}^{-2}$, the peak position is first blue-shifted, and then redshifted; the full-width at half-maximum (FWHM) first narrows, and then broadens. Another observation is that the peak intensity at first increases, then decreases and increases again.

Comparing the spectra of copper colloids at the LF value of 1 and $1.2 \mathrm{~J} \mathrm{~cm}^{-2}$, the plasmon peak intensity increases on increasing $\mathrm{LF}$ value up to $1.2 \mathrm{~J} \mathrm{~cm}^{-2}$, which indicates the increase in the concentration of NPs.

Furthermore, there is a blue-shift in the plasmon peak as the fluence increases, which can be attributed to changes in NP size, which is an effect of quantum confinement [29-31].

In the case of spectra at the LF value of 1.2 and $1.5 \mathrm{~J} \mathrm{~cm}^{-2}$, the increase of LF value is demonstrated to cause a red-shift 


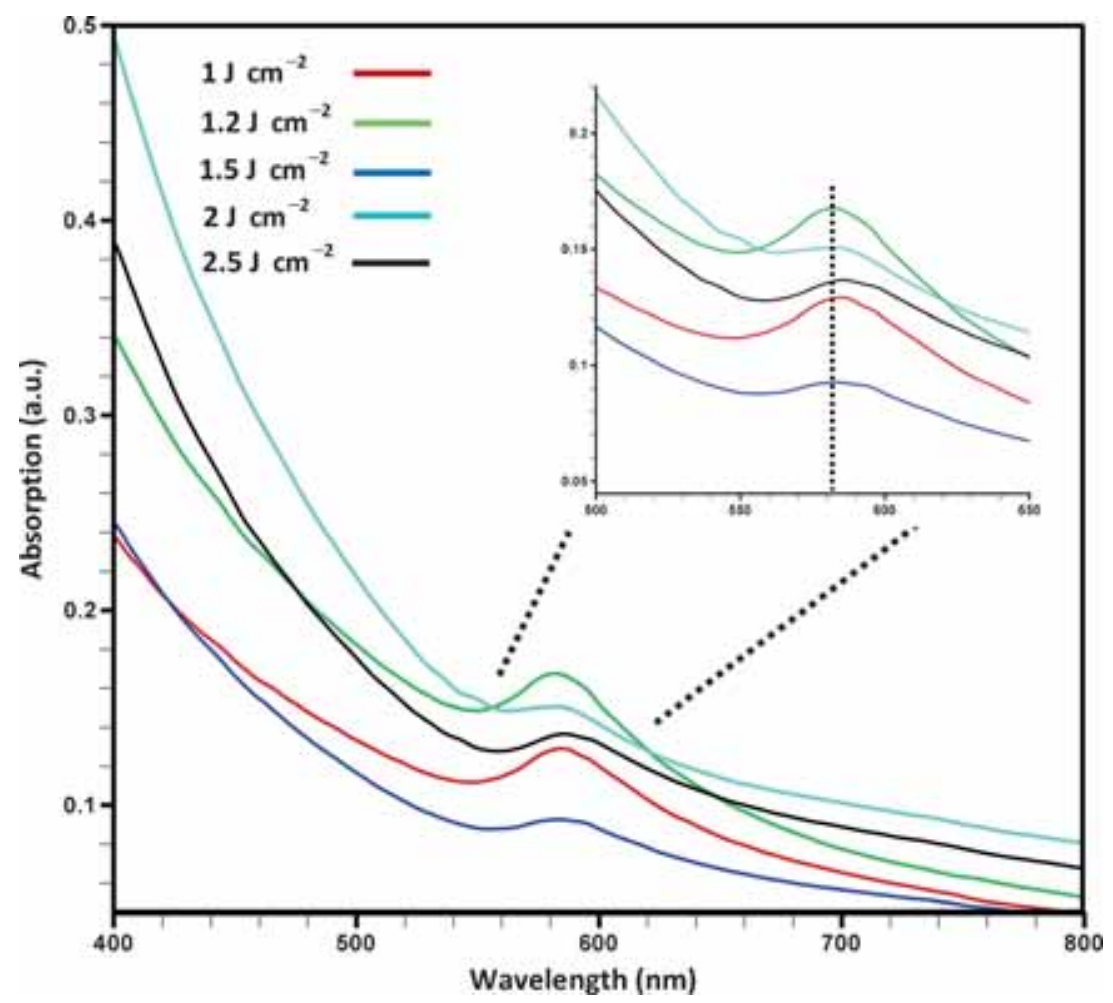

Figure 1. UV-vis spectra corresponding to copper colloids at different laser fluences in ethylene glycol as a solvent. The inset shows the shift in the absorption peak position.

(absorbance at longer wavelengths) in the plasmon peak position. Additionally, the intensity is lower than that achieved at $1.2 \mathrm{~J} \mathrm{~cm}^{-2}$. Red-shift in the plasmon peak ensures the increase in mean particle size and the presence of agglomerates. Also, red-shift can be related to scattering of light by particles that aggregate into big particles [1,21,31-34]. The peak intensity of NPs prepared at $1.2 \mathrm{~J} \mathrm{~cm}^{-2}$ is higher than that prepared at $1.5 \mathrm{~J} \mathrm{~cm}^{-2}$. This indicates that the amount of NPs (the productivity) prepared at $1.2 \mathrm{~J} \mathrm{~cm}^{-2}$ is more than that prepared at $1.5 \mathrm{~J} \mathrm{~cm}^{-2}$.

The narrower plasmon peak at the LF value of $1.2 \mathrm{~J} \mathrm{~cm}^{-2}$ indicates reduced amount of agglomerates, more homogeneity and narrower particle size distribution in colloids, which matched with TEM results, as shown in figure $2 \mathrm{a}[32,35,36]$.

When the LF value is $1.5 \mathrm{~J} \mathrm{~cm}^{-2}$, the peak is detectable but much weaker along with a long tail towards longer wavelengths. This probably indicates the formation of inhomogeneous sizes (poly-disperse colloids), very small particles, particle coalescence and agglomeration $[22,28,36]$.

In other words, the broadening of the spectrum may be due to change in distribution of particles, coalescence and particle shape in colloidal solutions [31,37]. Additionally, the intensity of the plasmon band at the LF value of $1.5 \mathrm{~J} \mathrm{~cm}^{-2}$ is much lower, suggesting smaller particle dimensions compared with other fluences [34].

For the sample at $1.2 \mathrm{~J} \mathrm{~cm}^{-2}$, there is an absorption peak at $582 \mathrm{~nm}$, which enhances with increasing LF value up to $2.5 \mathrm{~J} \mathrm{~cm}^{-2}$.
As a comparison, the absorption spectrum of synthesized colloidal solution for the $\mathrm{LF}$ value of $2 \mathrm{~J} \mathrm{~cm}^{-2}$ relative to that at $1.2 \mathrm{~J} \mathrm{~cm}^{-2}$ shows a red-shift in the position of the absorption peak. This shift shows that the particles are growing larger, as evident from particle size distribution in figure $4 \mathrm{~b}$.

Note that for the LF value of $1.2 \mathrm{~J} \mathrm{~cm}^{-2}$, the band is narrowed compared with that at $2 \mathrm{~J} \mathrm{~cm}^{-2}$, indicating a reduced amount of agglomerates and narrower particle size distribution in colloids, as confirmed by TEM analysis $[1,35]$.

It is remarkable that the peak with the highest intensity is obtained at the LF value of $1.2 \mathrm{~J} \mathrm{~cm}^{-2}$, compared with other fluences. The mass ablation rate is also higher at $1.2 \mathrm{~J} \mathrm{~cm}^{-2}$. Accordingly, at $1.2 \mathrm{~J} \mathrm{~cm}^{-2}$, the highest NP productivity is achieved [34]. On varying LF value from 1.5 to $2.5 \mathrm{~J} \mathrm{~cm}^{-2}$, the optical absorption shows a broad band, indicating the formation of inhomogeneous sizes and NPs agglomeration [36-38]. It is found that with increasing LF value from 1.5 to $2.5 \mathrm{~J} \mathrm{~cm}^{-2}$, the LSPR peak grows in intensity without any change in the position.

Thus, this result suggests an increase of particle density in solution with the increment of the LF value, while the mean particle size is almost the same $[17,29,30]$.

\subsection{Electron microscopy}

TEM analysis allows accurate measurement of particle average size, and is useful to investigate their crystalline or 
(a)

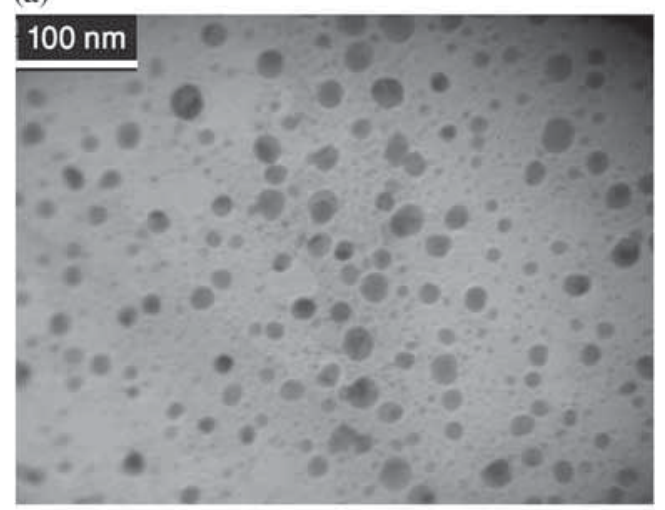

(b)

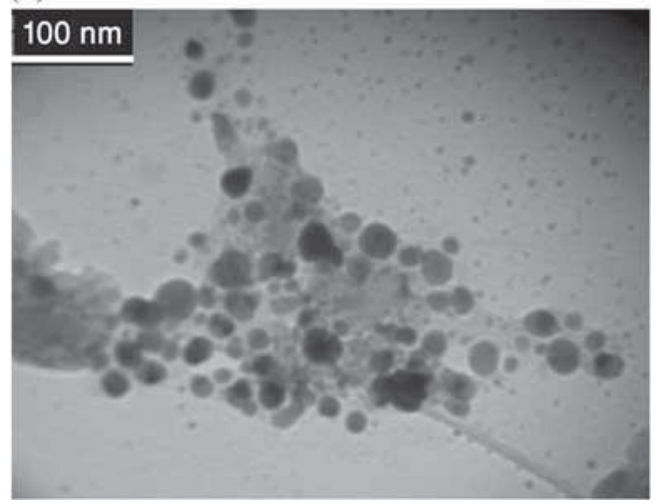

Figure 2. TEM images of $\mathrm{Cu}$ NPs on the scale of $100 \mathrm{~nm}$ prepared by ablation in ethylene glycol at different laser fluences. (a) 1.2 and (b) $2 \mathrm{~J} \mathrm{~cm}^{-2}$.

defective structure [39]. Mean particle size, size distribution and morphology of individual $\mathrm{Cu}$ NPs during laser ablation technique are confirmed through TEM analysis $[1,15]$.

Figures 2 and 3 illustrate typical TEM images of $\mathrm{Cu}$ colloidal NPs on the scale of 100 and $60 \mathrm{~nm}$ at different LFs of 1.2 and $2 \mathrm{~J} \mathrm{~cm}^{-2}$, respectively. These NPs are almost spherical in configuration. This morphology is likely due to creation of particles during thermal processes (quick solidification, melting and superheating) by nanosecond pulses, which results in the formation of NPs by explosive ejection [40].

It is interesting to note that at $1.2 \mathrm{~J} \mathrm{~cm}^{-2}$, particle dissipation is observed and well-separated copper NPs without agglomeration appear, as shown in figures $2 \mathrm{a}$ and $3 \mathrm{a}$. Laser ablation at $\mathrm{LF}$ value of $2 \mathrm{~J} \mathrm{~cm}^{-2}$ reveals a fraction of aggregated and coalesced NPs, and particle coagulation (figure 2b), as evident from the UV-vis spectrum.

On the other hand, colloidal particles prepared at $2 \mathrm{~J} \mathrm{~cm}^{-2}$ aggregate more easily than those prepared at $1.2 \mathrm{~J} \mathrm{~cm}^{-2}$, and the larger sizes are due to colloid fusion by ablation at a higher LF. It is confirmed that NPs produced at different $\mathrm{LF}$ values of 1.2 and $2 \mathrm{~J} \mathrm{~cm}^{-2}$ do not present the same uniformity. These results match with those from UV-vis spectra.

From TEM micrographs in figures 2 and 3 , one can notice also that the relative amount of $\mathrm{Cu}$ NPs at $1.2 \mathrm{~J} \mathrm{~cm}^{-2}$

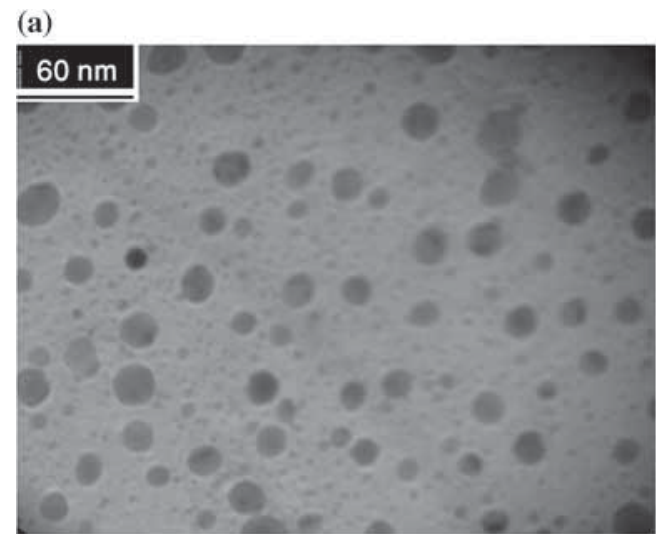

(b)

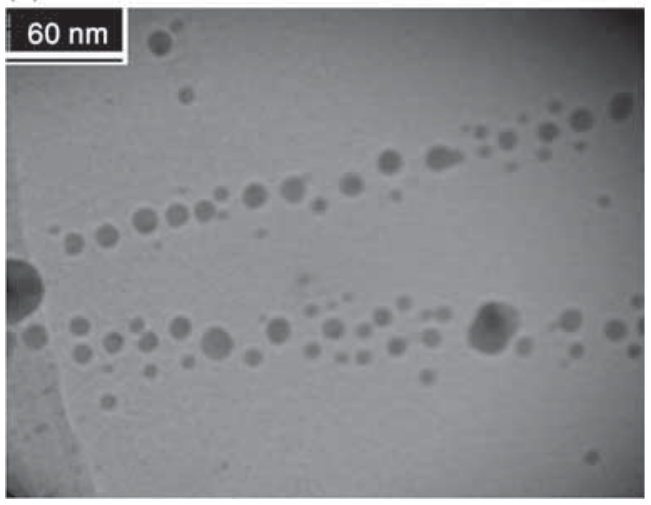

Figure 3. TEM images of $\mathrm{Cu}$ NPs on the scale of $60 \mathrm{~nm}$ prepared by ablation in ethylene glycol at different laser fluences. (a) 1.2 and (b) $2 \mathrm{~J} \mathrm{~cm}^{-2}$.

compared with that at $2 \mathrm{~J} \mathrm{~cm}^{-2}$ increases, which is compatible with UV-vis results.

Size distributions of copper NPs synthesized by laser ablation are determined by counting the diameter of about 300 NPs.

It should be noted that due to the sensitivity of NPs to their sizes, control of the particle size is essential [22].

Figure $4 \mathrm{a}$ and $\mathrm{b}$ illustrates the size distribution of colloidal NPs in EG solution at fluences of 1.2 and $2 \mathrm{~J} \mathrm{~cm}^{-2}$, respectively.

In our case, distribution of NPs with a mixture of different sizes is characterized using two log-normal functions at different LFs of 1.2 and $2 \mathrm{~J} \mathrm{~cm}^{-2}$, as seen from figure $4 \mathrm{a}$ and $b$.

It is obvious that at both LF values of 1.2 and $2 \mathrm{~J} \mathrm{~cm}^{-2}$, the size distributions are bi-modal and consist of two mean sizes and distinct maxima. In both cases, a large number of identical sphere-like NPs are obtained with diameters extending up to $3-33 \mathrm{~nm}$.

It is remarkable that the average particle sizes at $1.2 \mathrm{~J} \mathrm{~cm}^{-2}$ are smaller than that determined at $2 \mathrm{~J} \mathrm{~cm}^{-2}$. The mean particle sizes for each mode in the case of $1.2 \mathrm{~J} \mathrm{~cm}^{-2}$ are 5 and $16 \mathrm{~nm}$, whereas at $2 \mathrm{~J} \mathrm{~cm}^{-2}$, they are 7 and $24 \mathrm{~nm}$, respectively.

A much broader particle size distribution at the LF value of $2 \mathrm{~J} \mathrm{~cm}^{-2}$ is seen (figure $4 \mathrm{~b}$ ). These considerations suggest 
(a)

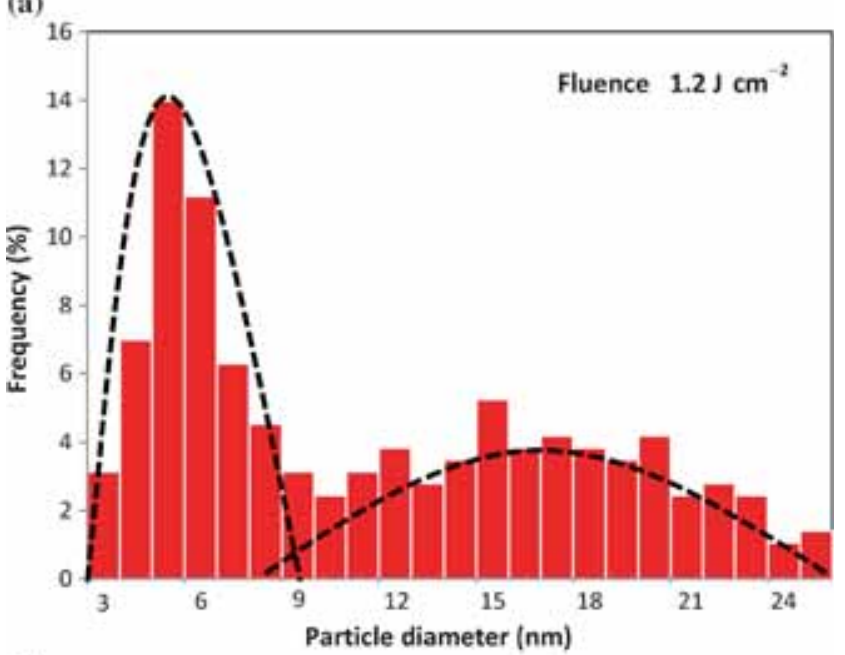

(b)

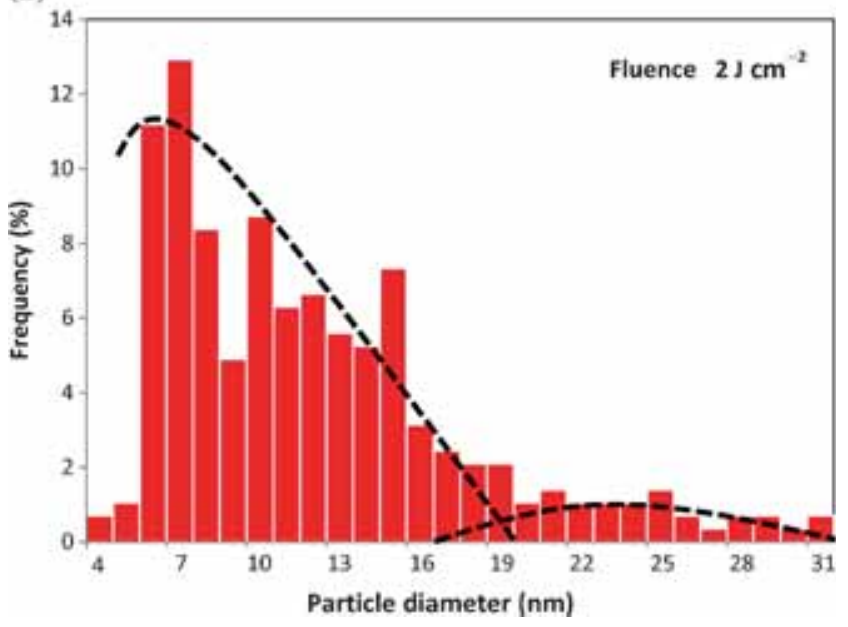

Figure 4. Particle size distribution of copper NPs prepared in ethylene glycol and their log-normal fit (solid lines) at different laser fluences. (a) 1.2 and (b) $2 \mathrm{~J} \mathrm{~cm}^{-2}$.

that in the case of $2 \mathrm{~J} \mathrm{~cm}^{-2}$, the particle size distribution is not uniform and homogeneous (also see figure 3b); this is consistent with the absorption spectra of figure 1 .

Furthermore, as previously reported by Simakin and Voronov [43], one of the reasons for the existence of a bimodal distribution (the small and large distributions) of NPs is the fragmentation of larger particles due to laserparticle interactions. Furthermore, the growth mechanism of NPs more than the laser ablation mechanism and laserinduced fragmentation may be determining the configuration of the size distribution.

In addition, these distributions are similar to those found by Nichols et al [41], Kabashina and Meunier [42] and Simakin and Voronov [43] for metal NPs in the literature.

They found that the probability of such a bimodal distribution depends on the various mechanisms of NPs formation.

On the other hand, the ejection of particles during or after laser ablation of the target surface is due to different mechanisms, such as coulomb explosion, melting through homogeneous nucleation, non-thermal melting, superheating,

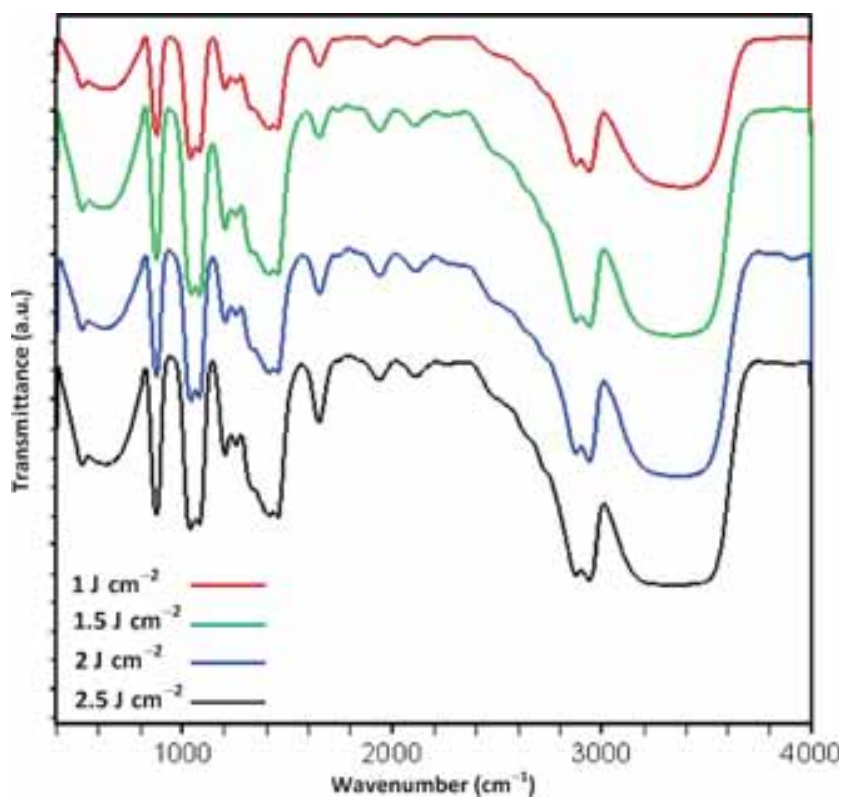

Figure 5. FTIR spectra of copper colloids obtained at various laser fluencies of 1, 1.5, 2 and $2.5 \mathrm{~J} \mathrm{~cm}^{-2}$.

vaporization etc., which can cause the NPs production by several methods $[16,41,42]$.

It should be noted that the origin of the presence of small and large particles (two distributions) in a bimodal size distribution may be correlated to non-thermal melting or phase explosion on the target surface during laser radiation, respectively $[41,42]$. Noticeably, a recent report from Messina also showed that the first part of the size distribution is generally attributed to the presence of metal NPs, which are produced by nucleation during plasma plume cooling followed by nuclei growth and coalescence [4].

\subsection{FTIR spectroscopy}

FTIR spectroscopy, a type of vibrational spectroscopy, is used to identify the stretching and bending frequencies of molecular functional groups attached to $\mathrm{Cu}$ NP surface [9,44-47].

Figure 5 reveals the FTIR spectra of copper NPs at various LF values. These spectra reveal a number of absorption peaks at different IR frequencies.

The absorption at distinct frequencies is related to several various modes of interatomic bond vibration (stretching or bending) and degrees of hydrogen bonding [48-51]. Assignments of FTIR characteristic bands of $\mathrm{Cu}$ NPs products at various LF values of $1,1.5,2$ and $2.5 \mathrm{~J} \mathrm{~cm}^{-2}$ are presented in table 1.

It is clear from figure 5 that the same functional groups are appearing in all samples at different LFs.

In all samples, there are broad and strong bands in the region $3327.43-3381.11 \mathrm{~cm}^{-1}$ ascribed to O-H (hydroxyl) stretching vibrations on the surface of copper NPs. They are the most intense and easily recognizable bands in the spectra 
Table 1. Assignments of the FTIR characteristic peaks (wavenumber, $\mathrm{cm}^{-1}$ ) of copper nanoparticle products at various laser fluences of $1,1.5,2$ and $2.5 \mathrm{~J} \mathrm{~cm}^{-2}$.

\begin{tabular}{|c|c|c|c|c|}
\hline \multicolumn{4}{|c|}{ Laser fluence $\left(\mathrm{J} \mathrm{cm}^{-2}\right)$} & \multirow[b]{2}{*}{ Assignment } \\
\hline 1 & 1.5 & 2 & 2.5 & \\
\hline 3381.11 & 3347.69 & 3368.33 & 3327.43 & $\mathrm{O}-\mathrm{H}$ stretching \\
\hline 2942.54 & 2942.91 & 2942.78 & 2944.01 & $\mathrm{C}-\mathrm{H}$ stretching \\
\hline 2877.89 & 2877.37 & 2877.84 & 2877.79 & $\mathrm{C}-\mathrm{H}$ stretching \\
\hline 2112.04 & 2114.03 & 2113.67 & 2113.61 & $\mathrm{Cu}-\mathrm{H}$ stretching \\
\hline 1941.37 & 1941.19 & 1941.10 & 1940.51 & $\mathrm{Cu}-\mathrm{H}$ stretching \\
\hline 1652.70 & 1653.43 & 1654.16 & 1652.62 & $\mathrm{O}-\mathrm{H}$ bending \\
\hline 1454.39 & 1454.29 & 1454.47 & 1454.97 & $\mathrm{C}-\mathrm{H}$ bending \\
\hline 1255.64 & 1254.81 & 1255.81 & 1255.74 & $\mathrm{C}-\mathrm{O}$ stretching \\
\hline 1204.92 & 1204.53 & 1205.01 & 1204.96 & $\mathrm{C}-\mathrm{O}$ stretching \\
\hline 1082.60 & 1083.68 & 1082.56 & 1082.34 & $\mathrm{C}-\mathrm{O}$ stretching \\
\hline 1040.25 & 1040.50 & 1040.33 & 1038.33 & C-O stretching \\
\hline 877.08 & 877.03 & 876.89 & 876.76 & $\mathrm{Cu}-\mathrm{O}-\mathrm{H}$ bending \\
\hline 645.61 & 622.72 & 633.04 & 634.95 & $\mathrm{Cu}-\mathrm{O}$ \\
\hline 523.98 & 522.59 & 522.54 & 522.90 & $\mathrm{Cu}-\mathrm{O}$ \\
\hline
\end{tabular}

of copper NPs. Also, their precise position depends on the strength of the hydrogen bonds [44,48,52-55].

In general, the width of the band is due to the degree of hydrogen bonding with neighbouring $\mathrm{OH}$ groups and alteration of intermolecular interaction strength in the sample. In this study, the bandwidth is nearly unaffected by LF value changes [48-51]. In all spectra, according to known standards, two bands in 2942.54-2944.01 and 2877.37$2877.89 \mathrm{~cm}^{-1}$ regions originate from $\mathrm{C}-\mathrm{H}$ (hydrocarbon) stretching vibrations in EG molecules [49-51,55].

Moreover, the peaks in the region $1454.29-1454.97 \mathrm{~cm}^{-1}$ give information about the bending vibration of $\mathrm{C}-\mathrm{H}$ bonds resulting from $\mathrm{CH}_{2}$ in $\mathrm{EG}$ chemical structure [55,57].

The weakly expressed bands in the region 2112.04 2114.03 and $1940.51-1941.37 \mathrm{~cm}^{-1}$ can be correlated to stretching of $\mathrm{Cu}-\mathrm{H}$ (metal-hydrogen) bond [50]. The absorption position of infrared bands is dependent on the force constant of a chemical bond, bond order, types of atoms joined by the bond and reduced mass. The bands at 1652.62$1654.16 \mathrm{~cm}^{-1}$ are characteristic of bending vibration of $\mathrm{O}-\mathrm{H}$ (hydroxyl) bonds in $\mathrm{OH}$ groups $[44,57,58]$.

The narrow peaks located between 1038 and $1255 \mathrm{~cm}^{-1}$ are consistent with those found by Zhu et al [59], which are associated with EG molecules.

The peaks in this region likely indicate the solvent $\mathrm{C}-\mathrm{O}$ groups on the surface of $\mathrm{Cu}$ NPs [49-51,55,56]. The narrow peaks are due to the weak intermolecular interactions in which the number of chemical environments is small, and these infrared bands can be observed. In the particular case of the metal-oxygen $(\mathrm{Cu}-\mathrm{O})$ bond, two main vibrational modes in the range of 622.72-645.61 and 522.54$523.98 \mathrm{~cm}^{-1}$, depending on the degree of hydrogen bonding, are observed. They demonstrate the formation of $\mathrm{CuO}$ NPs $[44,46,47,49-51,57,60]$. The peak intensity in the infrared spectra is determined by the concentration of molecules in the sample. In all IR spectra, the peak intensities belonging to the $\mathrm{Cu}-\mathrm{O}$ bonds are almost similar to each other, which confirms that the relative amount of $\mathrm{CuO}$ in all samples is the same [9,49-51]. Furthermore, the $\mathrm{Cu}-\mathrm{O}-\mathrm{H}$ bonds lead to bending absorptions in the region $876.76-877.08 \mathrm{~cm}^{-1}$, and shift in the bond position depends on the degree of hydrogen bonding $[49,54,55]$.

\section{Conclusions}

In summary, the laser ablation of bulk $\mathrm{Cu}$ in EG solvent at different LF values is investigated. The optical spectra of all samples reveal the LSPR bands located in the range of 582$584 \mathrm{~nm}$, which correspond to a yellowish-brown colour of the sample and formation of $\mathrm{Cu}$ NPs. Comparing $\mathrm{LF}$ value of 1 and $1.2 \mathrm{~J} \mathrm{~cm}^{-2}$, the higher absorption at $1.2 \mathrm{~J} \mathrm{~cm}^{-2}$, than at $2 \mathrm{~J} \mathrm{~cm}^{-2}$, implies a higher $\mathrm{Cu}$ colloidal concentration at $1.2 \mathrm{~J} \mathrm{~cm}^{-2}$ that matches with TEM results. It is found that with increasing LF from 1.2 to $2 \mathrm{~J} \mathrm{~cm}^{-2}$, the LSPR peak position is red-shifted and broadened, which show increasing particle sizes and coagulation of NPs, respectively. This is in good agreement with TEM results. Spherical NPs with diameters ranging over $3-33 \mathrm{~nm}$ at LF value of 1.2 and $2 \mathrm{~J} \mathrm{~cm}^{-2}$ can be found from TEM measurement. Furthermore, from FTIR spectroscopy, various atom groups adsorbed on the surface of colloidal NPs are determined.

\section{References}

[1] Ţălu Ş, Bramowicz M, Kulesza S, Shafiekhani A, Ghaderi A, Mashayekhi F and Solaymani S 2015 Ind. Eng. Chem. Res. 548212

[2] Ţălu Ş, Solaymani S, Bramowicz M, Naseri N, Kulesza S and Ghaderi A 2016 RSC Adv. 627228

[3] Ţălu Ş, Bramowicz M, Kulesza S, Solaymani S, Shafikhani A, Ghaderi A and Ahmadirad M 2016 J. Ind. Eng. Chem. 35158 
[4] Messina E 2012 PhD Thesis (Catania: Università degli Studi di Catania)

[5] Ramyadevi J, Jeyasubramanian K, Marikani A, Rajakumar G and Abdul Rahuman A 2012 Mater. Lett. 71114

[6] Hamad S, Krishna G, Gatlapalli P, Tewari S P and Venugopal Rao S 2014 J. Phys. 82331

[7] Santillán M J, Videla F A, Fernández van Raap M B, Schinca D C and Scaffardi L B 2013 J. Appl. Phys. 113 134305-1

[8] Khalaf Ali A 2010 PhD Thesis (Baghdad: University of Technology)

[9] Khalef W K 2013 J. Eng. Technol. 32396

[10] Sasaki T, Shimizu Y and Koshizaki N 2006 J. Photochem. Photobiol. A Chem. 182335

[11] Amendola V and Meneghetti M 2013 Phys. Chem. Chem. Phys. 153027

[12] Yan Z and Chrisey D B 2012 J. Photochem. Photobiol. C Photochem. Rev. 13204

[13] Salminen T 2013 PhD Thesis (Tampere: Tampere University of Technology)

[14] Desarkar H S, Kumbhakar P and Mitra A K 2012 Appl. Nanosci. 2285

[15] Samuel Golightly J 2007 PhD Thesis (Pennsylvania: Pennsylvania State University)

[16] Cristoforetti G, Pitzalis E, Spiniello R, Ishak R and MunizMiranda M 2011 J. Phys. Chem. C 1155073

[17] Khilkala W M, Al-Dahash G A and Abdul Wahid S N 2014 Int. J. Curr. Eng. Tech. 42577

[18] Itina T E 2011 J. Phys. Chem. C 1155044

[19] Amendola V and Meneghetti M 2009 Phys. Chem. Chem. Phys. 113805

[20] Miranda M, Gellini C and Giorgetti E 2011 J. Phys. Chem. C 1155021

[21] Jain P K, Huang X, El-Sayed I H and El-Sayed M A 2008 Acc. Chem. Res. 411578

[22] Xu B, Song R G, Tang P H, Wang J, Chai G Z, Zhang Y Z and Ye Z Z 2008 Key Eng. Mater. 373-374 346

[23] Sandu T 2012 J. Nanopart. Res. 141

[24] Haes A J, Paige Hall W, Chang L, Klein W L and Van Duyne R P 2004 Nano Lett. 41029

[25] Sherry L J, Chang S H, Schatz G C and Van Duyne R P 2005 Nano Lett. 52034

[26] Hashimoto S, Werner D and Uwada T 2012 J. Photochem. Photobiol. C Photochem. Rev. 1328

[27] Eustis S and El-Sayed M A 2005 Chem. Soc. Rev. 35 209

[28] Dung Dang $\mathrm{T}$ M, Thu Le T T, Fribourg-Blanc E and Chien Dang M 2011 Adv. Nat. Sci.: Nanosci. Nanotechnol. 2 015009-1

[29] Balamurugana B and Maruyama T 2005 Appl. Phys. Lett. 87 143105-1

[30] Intartaglia R, Bagga K, Brandi F, Das G, Genovese A, Di Fabrizio E and Diaspro A 2011 J. Phys. Chem. C 115 5102

[31] Fei B, Xin-Zheng Z, Zhen-Hua W, Qiang W, Hao H and JingJun X 2008 Chin. Phys. Lett. 254463

[32] Imam H, Elsayed K, Ahmed M A and Ramdan R 2012 Int. J. Opt. Photon. 273
[33] Yeh M S, Yang Y S, Lee Y P, Lee H F, Yeh Y H and Yeh C S 1999 J. Phys. Chem. B 1036851

[34] Hahn A, Barcikowski S and Chichkov B N 2008 J. Laser Micro/Nanoeng. 373

[35] Sajti C L, Petersen S, Jakobi J, Hahn A, Chichkov B N and Barcikowski S Proceedings of the ICCE-17 Conference, Hawaii, USA, p 1

[36] Chen Y H and Yeh C S 2002 Colloids Surf. A Physicochem. Eng. Aspects 197133

[37] Tsuji T, Iryo K, Watanabe N and Tsuji M 2002 Appl. Surf. Sci. 20280

[38] Mahmoud A K, Fadhill Z, Ibrahim Al-nassar S, Ibrahim Husein F, Akman E and Demir A 2013 J. Mater. Sci. Eng. B 3364

[39] Zamiri R, Zakaria A, Abbastabar Ahangar H, Darroudi M, Zamiri G, Rizwan Z and Drummen G P C 2013 Int. J. Nanomedicine $\mathbf{8} 233$

[40] Boutinguiza M, Comesaña R, Lusquiños F, Riveiro A and Pou J 2011 Nanoscale Res. Lett. 61

[41] Nichols W T, Sasaki T and Koshizaki N 2006 J. Appl. Phys. 100114912

[42] Kabashina A V and Meunier M 2003 J. Appl. Phys. 947941

[43] Simakin A V and Voronov V V 2004 Appl. Phys. A 791127

[44] Pramila Devamani R H and Sivakami S 2014 J. Sci. Res. 11

[45] Ndana M, Grace J J, Baba F H and Mohammed U M 2013 Int. J. Sci. Env. Technol. 21116

[46] Karthik A D and Geetha K 2013 J. Appl. Pharmac. Sci. 316

[47] Betancourt-Galindo R, Reyes-Rodriguez P Y, Puente-Urbina B A, Avila-Orta C A, Rodríguez-Fernández O S, CadenasPliego G, Lira-Saldivar R H and García-Cerda L A $2014 \mathrm{~J}$. Nanomater. 20141

[48] Henrist C, Traina K, Hubert C, Toussaint G, Rulmont A and Cloots R 2003 J. Cryst. Growth 254176

[49] Smith B 1999 Infrared spectral interpretation (New York: CRC Press, Taylor \& Francis Group)

[50] Stuart B H 2004 Infrared spectroscopy: fundamentals and applications (John Wiley \& Sons)

[51] Coates J 2000 In Encyclopedia of analytical chemistry R A Meyers (ed) (John Wiley \& Sons) p 10815

[52] Dadgostar N 2008 PhD Thesis (Waterloo: University of Waterloo)

[53] Suresh Y, Annapurnav S, Singh A K and Bhikshamaiah G 2014 Int. J. Innov. Res. Sci. Eng. Technol. 311265

[54] Mauricio Aguirre J, Gutiérrez A and Giraldo O 2011 J. Braz. Chem. Soc. 22546

[55] Socrates G 2001 (London: University of West London)

[56] Silverstein R M, Webster F X and Kiemle D J 2005 Spectrometric identification of organic compounds (New York: State University of New York, John Wiley \& Sons)

[57] Petrov T, Markova-Deneva I, Chauvet O, Nikolov R and Denev I 2012 J. Univ. Chem. Technol. Metall. 47197

[58] Suresh Y, Annapuma S, Bhikshamaiah G and Singh A K 2013 Proceedings of the international conference on advanced nanomaterials and emerging engineering technologies

[59] Zhu H, Lin Y and Yin Y 2004 J. Colloid Interface Sci. 277 100

[60] Rahman A, Ismail A, Jumbianti D, Magdalena S and Sudrajat H 2009 Indo. J. Chem. 9355 